\title{
Hantavirus pulmonary syndrome in a highly endemic area of Brazil
}

\author{
R. C. OLIVEIRA ${ }^{1 *}$, M. M. SANT'ANA ${ }^{2}$, A. GUTERRES ${ }^{1}$, J. FERNANDES $^{1}$, \\ N. L. F. K. HILLESHEIM ${ }^{3}$, C. LUCINI ${ }^{4}$, R. GOMES ${ }^{1}$, C. LAMAS ${ }^{5}$, \\ R. BOCHNER ${ }^{6}$, S. ZECCER ${ }^{2}$ AND E. R. S. DE LEMOS $^{1}$ \\ ${ }^{1}$ Laboratório de Hantaviroses e Rickettsioses, Instituto Oswaldo Cruz, Fiocruz, Rio de Janeiro, Rio de Janeiro, Brazil \\ ${ }^{2}$ Secretaria de Saúde do Estado de Santa Catarina, Setor de Vigilância Epidemiológica, Florianópolis, Santa \\ Catarina, Brazil \\ ${ }^{3}$ Secretaria Municipal de Saúde, Setor de Vigilância Epidemiológica, Concórdia, Santa Catarina, Brazil \\ ${ }^{4}$ Secretaria Municipal de Saúde, Setor de Vigilância Epidemiológica, Joaçaba, Santa Catarina, Brazil \\ ${ }^{5}$ Instituto Nacional de Infectologia Evandro Chagas, Fiocruz, Rio de Janeiro, RJ, Brazil \\ ${ }^{6}$ Laboratório de Informação Científica e Tecnológica em Saúde, Instituto de Comunicação e Informação \\ Científica e Tecnológica em Saúde, Fiocruz, Rio de Janeiro, RJ, Brazil
}

Received 16 April 2015; Final revision 15 September 2015; Accepted 17 September 2015; first published online 14 October 2015

\section{SUMMARY}

Hantavirus pulmonary syndrome (HPS) is the most frequently reported fatal rodent-borne disease in Brazil, with the majority of cases occurring in Santa Catarina. We analysed the clinical, laboratory and epidemiological data of the 251 confirmed cases of HPS in Santa Catarina in 1999-2011. The number of cases ranged from 10 to 47 per year, with the highest incidences in 2004-2006. Gastrointestinal tract manifestations were found in $>60 \%$ of the cases, potentially confounding diagnosis and leading to inappropriate therapy. Dyspnoea, acute respiratory failure, renal failure, increased serum creatinine and urea levels, increased haematocrits and the presence of pulmonary interstitial infiltrate were significantly more common in HPS patients who died. In addition, we demonstrated that the six cases from the midwest region of the state were associated with Juquitiba virus genotype. The case-fatality rate in this region, $19 \cdot 2 \%$, was lower than that recorded for other mesoregions. In the multivariate analysis increase of serum creatinine and urea was associated with death by HPS. Our findings help elucidate the epidemiology of HPS in Brazil, where mast seeding of bamboo can trigger rodent population eruptions and subsequent human HPS outbreaks. We also emphasize the need for molecular confirmation of the hantavirus genotype of human cases for a better understanding of the mortality-related factors associated with HPS cases in Brazil.

Key words: Brazil, case series, hantavirus pulmonary syndrome.

\section{INTRODUCTION}

Hantavirus pulmonary syndrome (HPS) is the most frequently reported fatal rodent-borne disease in
Brazil. Since 1993, when the first HPS cases were identified in Brazil, over 1800 cases have been reported, accounting for more than $45 \%$ of HPS cases reported

\footnotetext{
* Address for correspondence: Dr R. Carvalho de Oliveira, Pavilhão Hélio e Peggy Pereira, sala B115, Instituto Oswaldo Cruz, FIOCRUZ, Avenida Brasil 4365, Manguinhos, 21040-360, Rio de Janeiro/RJ, Brazil. (Email: reoliveira@ioc.fiocruz.br)
} 
in the Americas. HPS cases have been confirmed in 15 federated units, most of them in the southern, southeastern and midwestern regions of the country. The global case-fatality rate is $\sim 40 \%$ [1-3]. Of the Brazilian states, the southern state Santa Catarina (SC) has the largest proportion of cases $(15 \cdot 5 \%, 291 /$ 1876). Curiously, the mortality rate in this state is $\sim 29 \%$, less than that found in the rest of the country [3]. This difference in mortality rates is most likely due to variations in the virulence or circulation of hantavirus genotypes as well as differences in the genetic characteristics and immune status of the patients and the epidemiological surveillance systems and adequacy of supportive medical care available in different areas.

With its expansive territory $\left(8514215 \mathrm{~km}^{2}\right)$, Brazil occupies most of the eastern portion of South America. This large country supports several biomes with multiple natural ecosystems that account for the reported regional differences and temporal trends of HPS [4, 5], highlighting the need for region-specific studies. To date, six hantavirus genotypes have been identified as being associated with HPS in Brazil: Juquitiba (JUQV), Araraquara, Castelo dos Sonhos, Laguna Negra, Anajatuba and Rio Mamore. These viruses are transmitted by wild rodent reservoirs of the species Oligoryzomys nigripes, Necromys lasiurus, O. utiaritensis, Callomys callidus, O. mattogrossae and $O$. microtis, respectively [6-13]. Two other hantaviruses, not yet associated with human disease, have also been found in wild rodents in Brazil: Jabora (JABV), obtained from Akodon montensis in the southern region, and Rio Mearim, obtained from Holochilus sciureus in the northern region [8, 14].

HPS is a nationally reportable disease in Brazil, and its surveillance is based on serological methods, most commonly the detection of virus-specific immunoglobulin $\mathrm{M}(\operatorname{IgM})$ in serum using an enzyme immunoassay (EIA). The classification of 'confirmed' HPS requires signs and symptoms consistent with having the disease and at least one confirmatory laboratory finding or an epidemiological link to a confirmed HPS case. Rarely is an alternative diagnostic method, such as reverse transcription-polymerase chain reaction (RT-PCR), available for surveillance, and consequently, the molecular identification of the hantavirus responsible for a case is not routinely performed in Brazil [15].

This retrospective study reviews the clinical, laboratory, and epidemiological findings in HPS cases diagnosed in the state of SC from 1999 to 2011 and reports features and a molecular analysis of six HPS cases from the midwest region of this state. We also summarize recent findings of hantavirus rodent reservoir species identified in the municipality of Jaborá in our previous study [16], one of the areas where human illness has occurred and where we have demonstrated the co-circulation of two different hantavirus genotypes, JABV (not related to human disease) and JUQV. Based on these data, it was possible to associate the HPS cases over a 3-year period with the virus genotype circulating in rodent reservoirs and the occurrence of rodent outbreaks.

\section{MATERIALS AND METHODS}

\section{Study site}

SC, located in the southern region of Brazil, is $95736 \mathrm{~km}^{2}$ in size and has an estimated population of 6727148 people, with a population density of 65.27 inhabitants $/ \mathrm{km}^{2}$. The climate is humid subtropical. SC is divided into six mesoregions: (i) western $\mathrm{SC}$, (ii) southern $\mathrm{SC}$, (iii) northern SC, (iv) mountain, (v) the Vale do Itajaí and (vi) the Grande Florianópolis (Fig. 1). Geographically, SC is divided into a narrow coastal plain on the east and a large plateau on the west. The original vegetation of the state was comprised of both forests and fields. Forests, occupying $65 \%$ of this state, have been greatly reduced due to devastating deforestation. In the plateau, mixed forests of conifers (pines) and hardwoods exist, whereas in the lowland and the slopes of the Serra do Mar, only broad-leaved forest exists. Fields occur as scattered patches within the mixed forest.

The economy is based on industry (especially agribusiness, textiles, ceramics and metal-mechanical), extraction (mining) and livestock. The main agricultural product of SC is corn, grown in the basalt plateau which provides feed for pigs.

\section{Data analysis}

In this retrospective study, we reviewed all of the confirmed cases of HPS in SC reported to the national HPS surveillance system between 1999 and 2011. The anonymized secondary data including the demographic, epidemiological, clinical, laboratory and patient outcome data collected by the Health Bureau of the State of Santa Catarina (HSSSC) were analysed. 


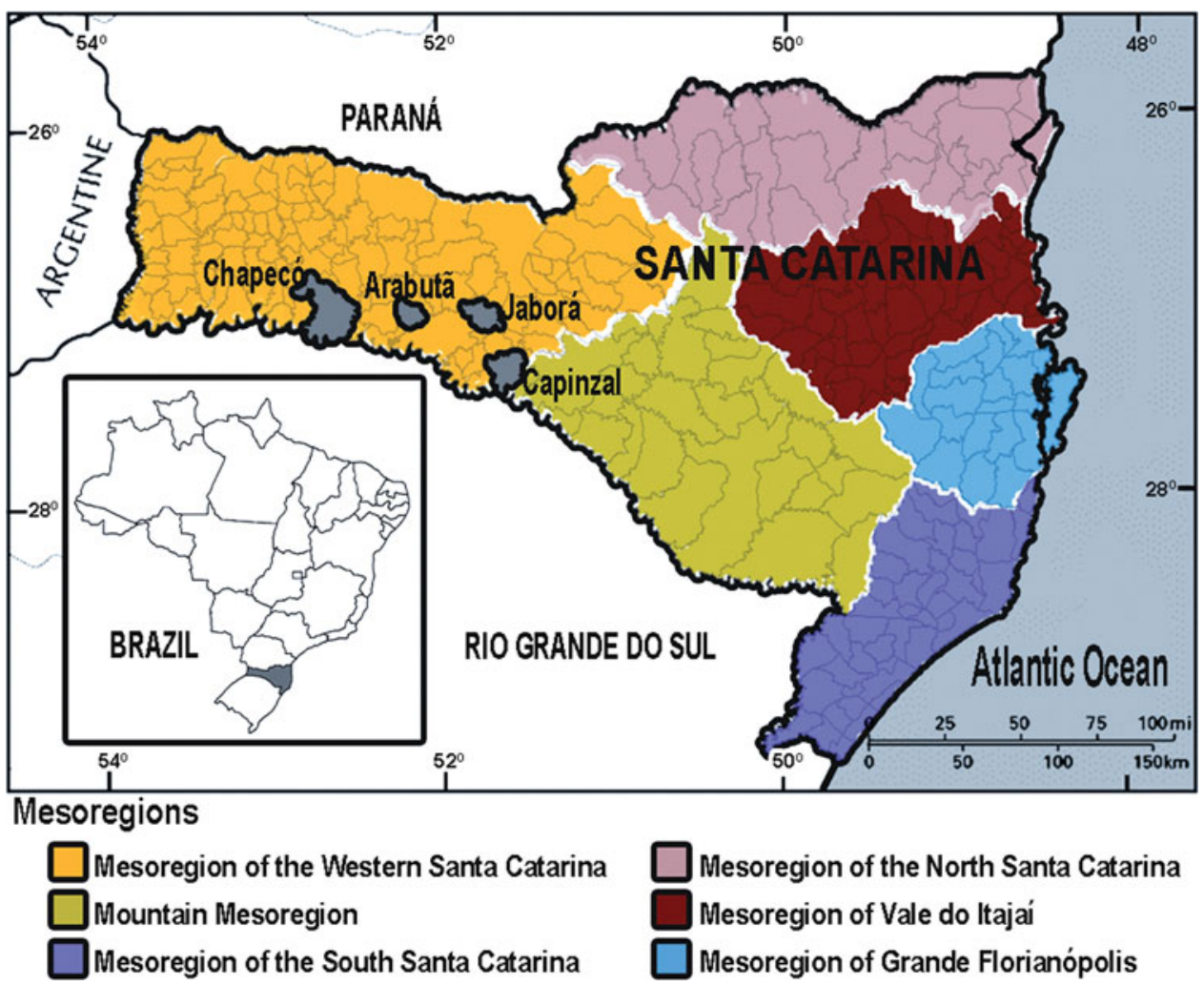

Fig. 1. Map of the state of Santa Catarina in southern Brazil, indicating the mesoregions (colours) and the municipalities where the six hantavirus pulmonary syndrome patients included in the molecular analysis lived (grey).

\section{Statistical analyses}

Descriptive statistics were used, and the data are expressed as absolute frequencies for the qualitative variables and as the mean \pm standard deviation for the quantitative variables. The $\chi^{2}$ test was employed to establish possible associations between death caused by HPS and epidemiological, clinical, laboratory and radiological variables, considering significance levels of $P<0.05$ and $95 \%$ confidence intervals (CIs). The analyses were performed using Microsoft Excel software v. 15.0 (Microsoft Corp., USA).

The odds ratio (OR) with $95 \%$ CI was used as a measure of association. For comparisons of more than two proportions, a logistic regression was performed to calculate the OR, using Epi Info v. 3.5.4 (CDC, USA).

In addition, a generalized linear model (GLM) analysis was performed in order to investigate the influence of independent variables on the response variable (evolution $=$ recovery or death). As variables that are non-significant in the univariate analysis can become significant once adjusted by other variables in a multivariable analysis, those that presented an association in the univariate analysis with $P \leqslant 0 \cdot 2$ were included in the first model. Following this, a forward-backward stepwise procedure was used and the variables in the first model with a $P$ value $<0 \cdot 1$ were retained in the final model. The OR of each variable was calculated and the $95 \%$ CI was used to confirm the effect of these independent variables on the response variable. All analyses were performed in R statistical software v. 2.13.1 (R Foundation for Statistical Computing, Austria).

The box-plot graphic was used to manually construct the class intervals when designing the map of HPS case numbers. This application of the box-plot function deserves attention because it aggregates information relevant to the map.

\section{HPS patients and molecular sampling}

Blood samples were collected from six patients in the western region of SC with HPS previously confirmed by a serological test (Fig. 1), and the extracted RNA was subjected to RT-PCR. Primers specific to the hantavirus $\mathrm{S}$ segment sequence were used to amplify and sequence the partial and complete genomic segment as reported previously $[17,18]$.

The partial $\mathrm{S}$ segment sequences obtained were aligned with Hantavirus sequences retrieved from 


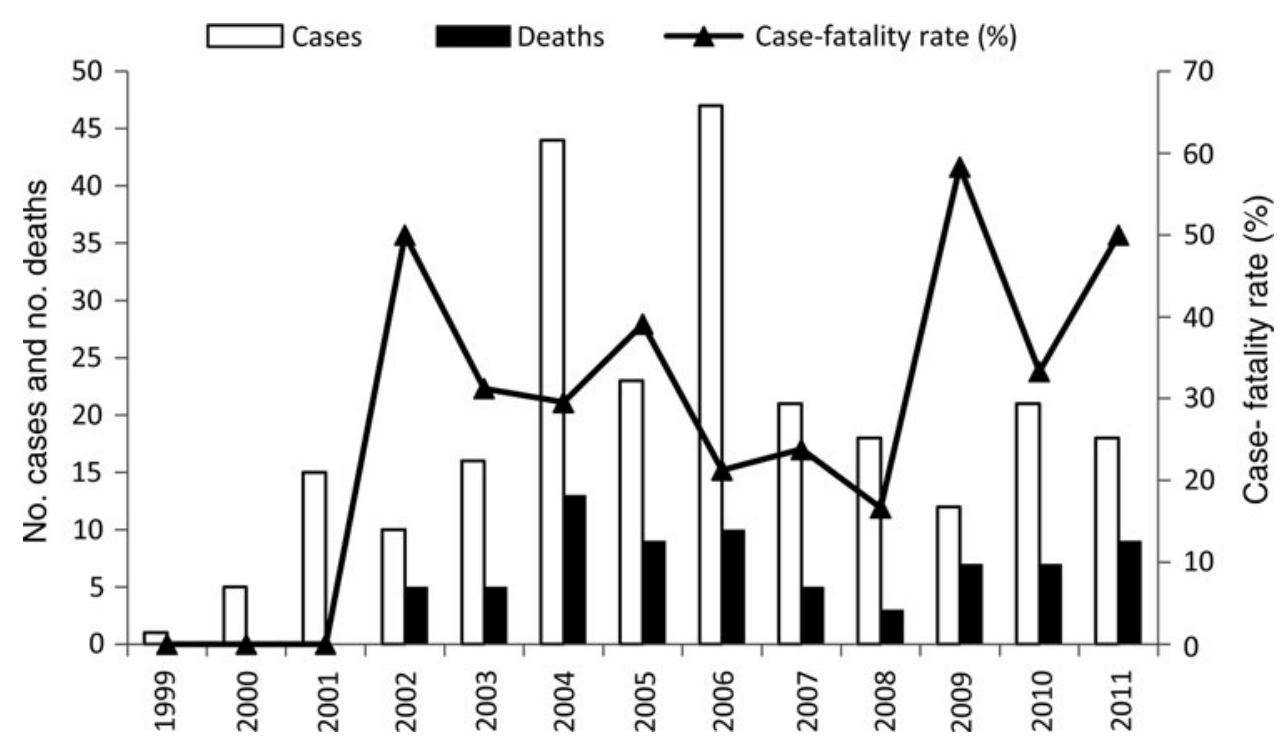

Fig. 2. Number of annual hantavirus pulmonary syndrome cases, related deaths and case-fatality rates in the state of Santa Catarina, Brazil (1999-2011).

GenBank. Multiple sequence alignment was performed using MUSCLE in SeaView v. 4 software [19]. The phylogenetic relationships were estimated by a Bayesian Markov Chain Monte Carlo (MCMC) method implemented in MrBayes v. 3.1.2 [20]. For the analyses, the sequence of Seoul virus (Genbank no. AY 627049 ) was used as the outgroup species.

Additional sequences retrieved from four $O$. nigripes specimens trapped in the Jaborá municipality, Oln8057 (Genbank accession no. JX 173 803), Oln8091 (Genbank accession no. JX 173 804), Oln9592 (Genbank accession no. JX 173 805), and Oln9845 (Genbank accession no. JX 173 806), were included in the analysis. These samples were obtained during ten small mammal capture expeditions that were conducted between 2004 and 2006 in the municipality of Jaborá in our previous study [16].

\section{Ethics statement}

The Ethics Review Board of the Oswaldo Cruz Foundation (FIOCRUZ) approved the project under no. 559/10. Informed consent was obtained from HPS patients from the midwest region of SC whose blood was used in the molecular sampling study.

\section{RESULTS}

\section{Epidemiological, clinical and laboratory findings}

During the study period, November 1999 to December 2011, 251 HPS cases were reported to the HSSSC. The majority $(93 \cdot 2 \%)$ of these cases were confirmed by serological assay, but $17(6 \cdot 8 \%)$ cases were only confirmed using clinical-epidemiological criteria. Of the cases confirmed by serology, nine cases were also confirmed by RT-PCR, and nine processed samples were confirmed by immunohistochemistry. Only one case was confirmed by three specific tests.

The distribution of cases in SC during the study period is shown in Figure 2. The highest annual number of HPS cases was observed in $2006(n=47)$, followed by $2004(n=44)$. The global case-fatality rate during the period from 1999 to 2011 was $29 \cdot 1 \%$, with annual rates ranging from zero (1999 and 2000) to $58 \cdot 3 \%$ (2009). The morbidity and fatality rates were 0.3 and 0.9 cases/million persons, respectively. Cases occurred throughout the year, although November and December were the peak months of illness onset (data not shown). During the study period, the western SC mesoregion accounted for $49.8 \%$ of HPS cases but had the lowest case-fatality rate $(19 \cdot 2 \%)$. Cases occurred in all six mesoregions, including a total of 113 municipalities, but only four $(1.59 \%)$ cases have been confirmed in the southern SC mesoregion since 2008 (Fig. 3). In the second most frequently affected region, the Vale do Itajai (19.5\% of cases), the case-fatality rate was high $(48.9 \%)$. The case-fatality rates in the different geographical mesoregions varied significantly and the highest proportions of fatal cases were seen in patients from north SC $(P=0 \cdot 01)$ and the Vale do Itajai $(P<0 \cdot 01)$ regions, where the analysis of ORs for death by HPS were $4 \cdot 13$ and $3 \cdot 96$, respectively (Table 1 ). The morbidity rate ranged 


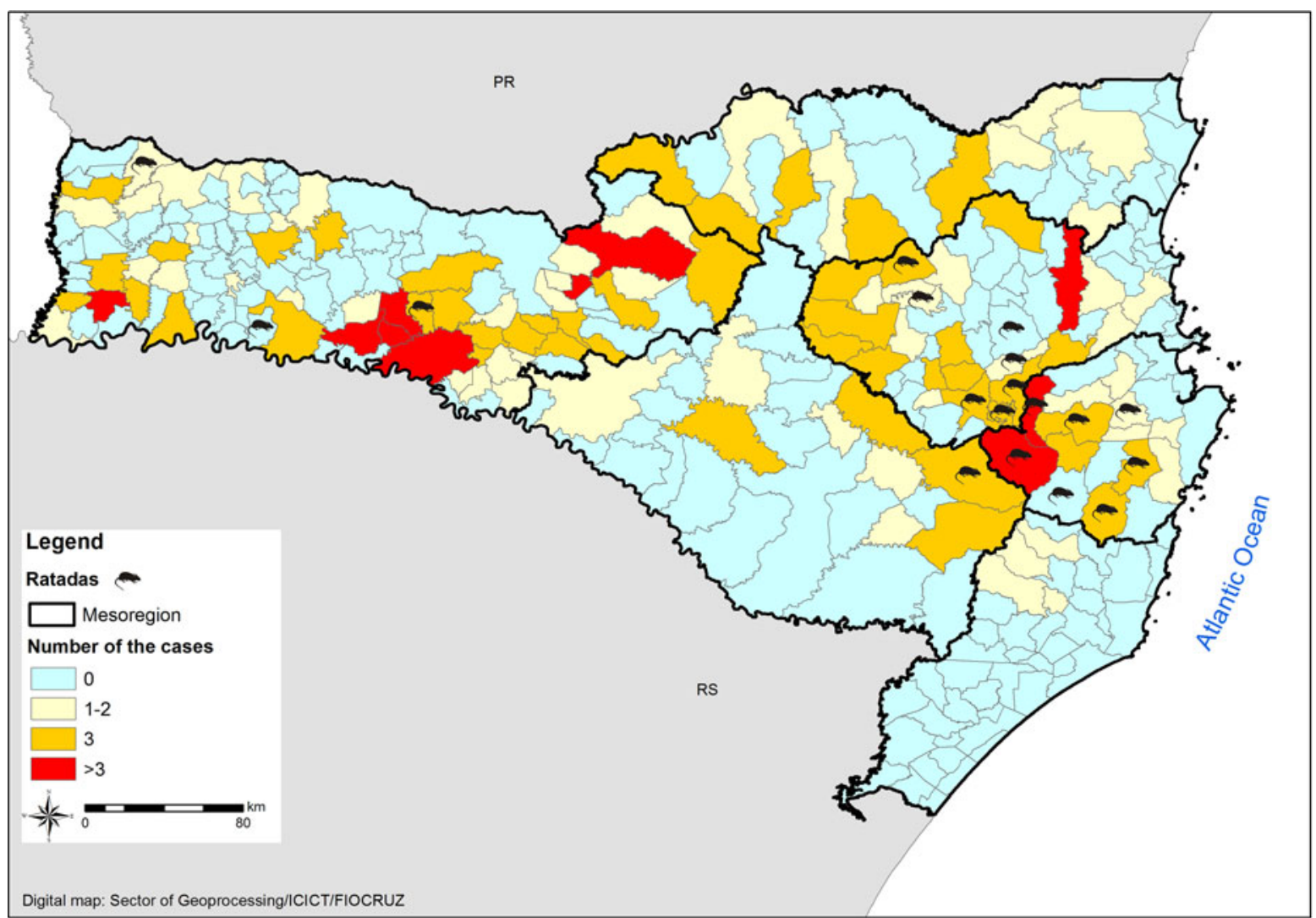

Fig. 3. Hantavirus pulmonary syndrome case distributions in Santa Catarina (SC) and its mesoregions in 1999-2011. The number of cases is represented by class intervals indicated by the colors. Rodent outbreaks or ratadas reported in some municipalities of SC during 2004-2006 are represented by rat images on the map.

from 0.03 cases/million persons in the south to 0.83 cases/million persons in the west.

In general, since 1999, most of the HPS cases in SC have occurred in the western and midwestern regions of the state, although a number of cases were reported in the eastern region in 2002, and in 2004 other mesoregions were affected. From 2004 to 2006, 18 municipalities reported rodent outbreaks after bamboo mast events; 15 of these events were associated with confirmed HPS cases (Fig. 3).

The data analysis of HPS cases collected by HSSSC showed that the mean HPS patient age was $34.560 \pm$ $13 \cdot 381$ years (range 0-73 years). Most patients (74/ $250,29 \cdot 6 \%$ ) were aged between 40 and 49 years, and $61 / 250(24 \cdot 4 \%)$ were aged $30-39$ years. No deaths were observed in children aged $<10$ years, an age group that accounts for $2 \cdot 8 \%$ of the cases. No significant difference in case-fatality rates were noted in the age groups (Table 1).

The HPS population had a higher proportion of males than females $(80 \cdot 8 \%$ vs. $19 \cdot 1 \%)$; the male/female ratio was 203/48 (4·2/1) (Table 1$)$. The case-fatality rate between genders was not significantly different: $33 \cdot 3 \%$ females $v$ s. $28 \cdot 1 \%$ males $(P=0 \cdot 47)$ (Table 1$)$.

The probable site of infection was related to the rural environment in $164 / 234$ cases $(70 \cdot 1 \%)$, and 150/234 HPS patients $(64 \cdot 1 \%)$ reported contact with rodents or rodent excreta (Table 1). An occupational exposure that includes agricultural, livestock and forest activities was reported by $108 / 180$ patients $(60 \%)$ for whom such information was available.

The frequencies of selected clinical and laboratory findings available from the health service archive are reported in Table 2. We compared them with the main published series in Brazil (Table 3). Fever was the most consistent symptom, present in $95 \%$ of HPS cases (233/246). The other most common nonspecific clinical findings were headache $(88 \cdot 3 \%)$, myalgia $(74 \cdot 1 \%)$, vomiting $(77 \%)$ and abdominal pain (63.6\%). More specific and frequent clinical findings were thoracic pain $(53 \cdot 4 \%)$, dyspnoea $(72 \cdot 1 \%)$, cough $(61 \cdot 3 \%)$ and acute respiratory failure $(43 \cdot 8 \%)$. Acute renal failure was observed in $33.0 \%$ of HPS patients, and petechiae and/or bleeding were observed in $15 \%$ 
Table 1. Epidemiological characteristics of hantavirus pulmonary syndrome (HPS) cases in the state of Santa Catarina, Brazil (1999-2011)

\begin{tabular}{|c|c|c|c|c|c|c|}
\hline \multirow[b]{2}{*}{ Characteristic* } & \multirow[b]{2}{*}{$\begin{array}{l}\text { No. patients/no. patients } \\
\text { for whom data were } \\
\text { available }(\%)\end{array}$} & \multicolumn{5}{|l|}{ Outcome } \\
\hline & & $\begin{array}{l}\text { No. } \\
\text { patients } \\
\text { who died }\end{array}$ & $\mathrm{CFR}, \% \dagger$ & $95 \% \mathrm{CI}^{3}$ & $P$ valuet & OR $(95 \% \mathrm{CI})$ \\
\hline \multicolumn{7}{|l|}{ Sex } \\
\hline Male & $203 / 251(80 \cdot 8)$ & 57 & $28 \cdot 1$ & $(21 \cdot 9-34 \cdot 3)$ & $0 \cdot 47$ & $0 \cdot 80(0 \cdot 40-1 \cdot 60)$ \\
\hline Female & $48 / 251(19 \cdot 1)$ & 16 & $33 \cdot 3$ & $(20 \cdot 0-46 \cdot 7)$ & & \\
\hline \multicolumn{7}{|l|}{ Age group (years) } \\
\hline$<10$ & $7 / 250(2 \cdot 8)$ & 0 & $0 \cdot 0$ & $(0 \cdot 0-0 \cdot 0)$ & - & - \\
\hline $10-19$ & $26 / 250(10 \cdot 4)$ & 07 & $26 \cdot 9$ & $(9 \cdot 9-44 \cdot 0)$ & $0 \cdot 86$ & $1 \cdot 10(0 \cdot 37-3 \cdot 23)$ \\
\hline $20-29$ & $56 / 250(22 \cdot 4)$ & 22 & $39 \cdot 2$ & $(26 \cdot 5-52 \cdot 1)$ & $0 \cdot 07$ & $2 \cdot 01(0 \cdot 93-4 \cdot 33)$ \\
\hline $30-39$ & $61 / 250(24 \cdot 4)$ & 16 & $26 \cdot 2$ & $(15 \cdot 2-37 \cdot 3)$ & $0 \cdot 79$ & $1 \cdot 11(0 \cdot 50-2 \cdot 44)$ \\
\hline $40-49$ & $74 / 250(29 \cdot 6)$ & 18 & $24 \cdot 3$ & $(14 \cdot 5-34 \cdot 1)$ & & Reference \\
\hline$>50$ & $26 / 250(10 \cdot 4)$ & 09 & $34 \cdot 6$ & $(16 \cdot 3-53 \cdot 0)$ & $0 \cdot 26$ & $1 \cdot 75(0 \cdot 65-4 \cdot 68)$ \\
\hline \multicolumn{7}{|l|}{ Mesoregions } \\
\hline Western Santa Catarina & $125 / 248(50 \cdot 4)$ & 24 & $19 \cdot 2$ & $(12 \cdot 3-26 \cdot 1)$ & & Reference \\
\hline South Santa Catarina & $4 / 248(1 \cdot 6)$ & 02 & $50 \cdot 0$ & $(1 \cdot 0-99 \cdot 0)$ & $0 \cdot 16$ & $4 \cdot 12(0 \cdot 55-30 \cdot 79)$ \\
\hline North Santa Catarina & $18 / 248(7 \cdot 3)$ & 09 & $50 \cdot 0$ & $(27 \cdot 0-73 \cdot 1)$ & $0 \cdot 01$ & $4 \cdot 13(1 \cdot 48-11 \cdot 50)$ \\
\hline Mountain & $13 / 248(5 \cdot 2)$ & 03 & $23 \cdot 1$ & $(0 \cdot 2-46 \cdot 0)$ & 0.65 & $1 \cdot 37(0 \cdot 34-5 \cdot 46)$ \\
\hline Vale do Itajaí & $49 / 248(19 \cdot 8)$ & 24 & $48 \cdot 9$ & $(35 \cdot 0-63 \cdot 0)$ & $<0 \cdot 01$ & $3.96(1 \cdot 94-8 \cdot 10)$ \\
\hline Grande Florianópolis & $39 / 248(15 \cdot 7)$ & 10 & $25 \cdot 6$ & $(12 \cdot 0-39 \cdot 3)$ & $0 \cdot 37$ & $1 \cdot 47(0 \cdot 63-3 \cdot 44)$ \\
\hline \multicolumn{7}{|l|}{ Probable infection site } \\
\hline Rural & $164 / 231(71 \cdot 0)$ & 46 & $28 \cdot 0$ & $(21 \cdot 2-34 \cdot 9)$ & $0 \cdot 47$ & $0 \cdot 78(0 \cdot 42-1 \cdot 47)$ \\
\hline Urban & $67 / 231(29 \cdot 0)$ & 22 & $32 \cdot 1$ & $(21 \cdot 6-44 \cdot 1)$ & & \\
\hline
\end{tabular}

OR, Odds ratio; CI, confidence interval.

* Data not available in all HPS cases.

$\dagger$ Case-fatality rate for all case-patients.

$\ddagger P$ value for testing the difference in proportion of HPS case-patients who died between categories for each characteristic.

of the patients. Neurological manifestations were apparent in $11 \%$ of the patients.

Blood tests revealed thrombocytopenia in $73 \%$, leukocytosis in $45 \cdot 1 \%$ and atypical lymphocytes in $34 \cdot 7 \%$ of HPS patients. Chest radiographs, when available, showed diffuse pulmonary infiltrates in $121 / 192$ cases $(62 \cdot 3 \%)$.

Dyspnoea, acute respiratory failure, renal failure, increased haematocrits, increased serum creatinine and blood urea nitrogen (BUN) levels, and the presence of pulmonary interstitial infiltrate were significantly more common in HPS patients who died than in HPS patients who survived $(P<0 \cdot 001)$ (Table 2). According to univariate analyses these clinical and laboratory variables mentioned above, and also fever, thoracic pain, thrombocytopenia and the presence of atypical lymphocytes $(P<0 \cdot 2)$, age group $(20-29$ years, $P=0.07$ ) and localities (mesoregions, $P \leqslant 0.01$ ) were considered for the first model in GLM. The only retained variables in the model were localities (mesoregions) and increase of BUN and creatinine levels, although only the later was significant by OR and 95\% CI (Table 4), indicating that this variable were statistically associated with evolution to death.

Patients were hospitalized in $236 / 245$ cases $(96 \cdot 3 \%$ ), and the fatality rate was $30 \cdot 1 \%$. The mean time from onset of symptoms to death was $3.6 \pm 3.8$ days. The patients were treated with mechanical ventilation in $94 / 227$ cases $(41 \cdot 4 \%)$ for which data were available. Antiviral treatment with ribavirin was used in only 21 patients, and $15(71.4 \%)$ of these patients recovered. No information on the use of vasoactive agents was available in the database.

\section{Molecular data}

For the six HPS cases in which a molecular analysis was performed (Supplementary Table S1), the nucleotide sequences of the $\mathrm{S}$ segment of viral RNA confirmed a JUQV infection. Five patients were included in the phylogenetic analysis and grouped with a well-supported clade composed of JUQ- 
Table 2. Clinical and laboratory characteristics of hantavirus pulmonary syndrome (HPS) cases in the state of Santa Catarina, Brazil (1999-2011)

\begin{tabular}{|c|c|c|c|c|c|c|}
\hline \multirow[b]{2}{*}{$\begin{array}{l}\text { Clinical and laboratory } \\
\text { findings* }\end{array}$} & \multirow[b]{2}{*}{$\begin{array}{l}\text { No. patients/no. patients } \\
\text { For whom data were } \\
\text { available }(\%)\end{array}$} & \multicolumn{5}{|l|}{ Outcome } \\
\hline & & $\begin{array}{l}\text { No. } \\
\text { patients } \\
\text { who died }\end{array}$ & CFR, $\% \dagger$ & $95 \% \mathrm{CI}$ & $P$ value & OR $(95 \% \mathrm{CI})$ \\
\hline Fever & $233 / 246(95 \cdot 2)$ & 67 & $28 \cdot 7$ & $(23 \cdot 0-34 \cdot 3)$ & $0 \cdot 11$ & $2 \cdot 44(0 \cdot 71-8 \cdot 26)$ \\
\hline Dyspnoea & $175 / 243(72 \cdot 1)$ & 67 & $38 \cdot 3$ & $(30 \cdot 9-44 \cdot 0)$ & $<0 \cdot 001$ & $7 \cdot 15(3 \cdot 07-22 \cdot 33)$ \\
\hline Cough & $149 / 244(61 \cdot 3)$ & 46 & $30 \cdot 9$ & $(23 \cdot 5-37 \cdot 6)$ & $0 \cdot 64$ & $0 \cdot 84(0 \cdot 45-1 \cdot 53)$ \\
\hline Acute respiratory failure & $107 / 245(43 \cdot 8)$ & 53 & $49 \cdot 5$ & $(39 \cdot 3-52 \cdot 0)$ & $<0 \cdot 001$ & $6 \cdot 15(3 \cdot 32-11 \cdot 52)$ \\
\hline Myalgia & $179 / 243(74 \cdot 1)$ & 55 & $30 \cdot 7$ & $(24 \cdot 6-36 \cdot 3)$ & $0 \cdot 61$ & $0 \cdot 80(0 \cdot 40-1 \cdot 53)$ \\
\hline Headache & $214 / 243(88 \cdot 3)$ & 60 & $28 \cdot 0$ & $(22 \cdot 0-33 \cdot 2)$ & $0 \cdot 55$ & $1 \cdot 40(0 \cdot 54-3 \cdot 43)$ \\
\hline Vomiting & $189 / 244(77 \cdot 0)$ & 56 & $29 \cdot 6$ & $(23 \cdot 8-35 \cdot 5)$ & $0 \cdot 95$ & $0 \cdot 96(0 \cdot 47-1 \cdot 88)$ \\
\hline Thoracic pain & $131 / 243(53 \cdot 4)$ & 43 & $32 \cdot 8$ & $(25 \cdot 2-39 \cdot 7)$ & $0 \cdot 16$ & $0 \cdot 64(0 \cdot 36-1 \cdot 13)$ \\
\hline Abdominal pain & $155 / 243(63 \cdot 6)$ & 47 & $30 \cdot 3$ & $(23 \cdot 2-35 \cdot 5)$ & $0 \cdot 70$ & $0 \cdot 85(0 \cdot 46-1 \cdot 53)$ \\
\hline Renal failure & $38 / 241(33 \cdot 0)$ & 20 & $52 \cdot 6$ & $(36 \cdot 9-66 \cdot 0)$ & $<0 \cdot 001$ & $3 \cdot 43(1 \cdot 66-7 \cdot 16)$ \\
\hline Petechiae and/or bleeding & $40 / 242(14 \cdot 5)$ & 14 & $3 \cdot 5$ & $(0 \cdot 00-7 \cdot 00)$ & $0 \cdot 49$ & $1 \cdot 37(0 \cdot 66-2 \cdot 81)$ \\
\hline Haematocrit $>50$ & $113 / 207(54 \cdot 7)$ & 47 & $41 \cdot 6$ & $(32 \cdot 8-49 \cdot 6)$ & $<0 \cdot 001$ & $4 \cdot 35(2 \cdot 20-8 \cdot 99)$ \\
\hline Atypical lymphocytes & $68 / 182(34 \cdot 7)$ & 27 & $39 \cdot 7$ & $(28 \cdot 0-50 \cdot 0)$ & $0 \cdot 07$ & $1 \cdot 88(0 \cdot 94-3 \cdot 76)$ \\
\hline Thrombocytopenia & $152 / 179(45 \cdot 1)$ & 53 & $34 \cdot 9$ & $(27 \cdot 6-40 \cdot 8)$ & $0 \cdot 08$ & $2 \cdot 22(0 \cdot 92-5 \cdot 97)$ \\
\hline Leukocytosis & $111 / 204(54 \cdot 4)$ & 32 & $38 \cdot 5$ & $(32 \cdot 4-44 \cdot 1)$ & $0 \cdot 89$ & $1 \cdot 00(0 \cdot 54-1 \cdot 88)$ \\
\hline $\begin{array}{l}\text { Increase of BUN and } \\
\text { creatinine }\end{array}$ & $65 / 171(38 \cdot 0)$ & 33 & $50 \cdot 8$ & $(38 \cdot 5-61 \cdot 5)$ & $<0 \cdot 001$ & $3 \cdot 80(1.94-7 \cdot 56)$ \\
\hline $\begin{array}{l}\text { Diffuse pulmonary } \\
\text { infiltrate }\end{array}$ & $121 / 192(62 \cdot 3)$ & 52 & $43 \cdot 0$ & $(33 \cdot 9-50 \cdot 4)$ & $<0 \cdot 001$ & $6 \cdot 92(3 \cdot 03-17 \cdot 61)$ \\
\hline
\end{tabular}

OR, Odds ratio; CI, confidence interval; BUN, blood urea nitrogen.

* Data not available in all HPS cases.

$\uparrow$ Case-fatality rate for all case-patients.

t $P$ values were determined by $\chi^{2}$ test, excepted for fever data, which was evaluated by Fisher's exact test, for testing the difference in proportion of HPS case-patients who died between categories for each characteristic.

like viruses, as shown in the phylogenetic tree (Supplementary Fig. S1). A complete sequence of the JUQV S segment ( 1900 bp) was obtained from one of the human HPS samples (case 4, LH0076/11) and was also included in the phylogenetic analysis (Genbank accession no. JX 173 798).

Figure 4 shows the number of HPS cases occurring between 2004 and 2006 in the municipality of Jaborá in association with the number of infected wild rodents captured during the same period [16]. In this hantavirus-reservoir study, both JABV and JUQV genotypes were identified in $8 / 10$ trapping expeditions; in December 2005 and 2006, only JUQV was found. The highest incidence of HPS cases was found in November and December and was associated with the highest number of animals infected with JUQV.

\section{DISCUSSION}

The present study assessed the clinical, epidemiological and laboratory characteristics of patients with HPS and identified the hantavirus genotype responsible for causing human infection in the midwestern portion of SC, Brazil. The frequency of the clinical and laboratory findings was in accordance with other studies conducted in Brazil, with fever, myalgia and headache being the most frequently reported clinical manifestations [21-24]. Gastrointestinal tract manifestations such as vomiting and abdominal pain, which can confound the diagnosis and lead to inappropriate therapy, were found in $77 \%$ and $63.3 \%$ of the patients, respectively. Although renal failure is not a common symptom of HPS, it was associated with a case-fatality rate of $52 \cdot 6 \%$; most of the fatalities $(80 \%)$ occurred within 5 days of onset of symptoms. According to the multivariable analysis, high serum urea nitrogen and creatinine levels are significantly associated with death, emphasizing the importance of biochemical analysis. As noted for other Brazilian regions, most cases of HPS are associated with the rural environment, where biochemical specific assays are usually not performed, only X-ray and complete blood count 
Table 3. Clinical and laboratory findings in patients diagnosed with hantavirus pulmonary syndrome in Brazil in the present study and in other published series

\begin{tabular}{|c|c|c|c|c|c|c|}
\hline \multirow[b]{2}{*}{$\begin{array}{l}\text { Clinical and } \\
\text { laboratoryfindings }\end{array}$} & \multicolumn{6}{|c|}{ Patients, no. (\%) } \\
\hline & $\begin{array}{l}\text { Raboni et al. } \\
2005[21] \\
(N=98)\end{array}$ & $\begin{array}{l}\text { HSS } 2007 \\
{[40](N=187)}\end{array}$ & $\begin{array}{l}\text { Limongi } \\
\text { et al. } 2007 \\
{[22](N=23)}\end{array}$ & $\begin{array}{l}\text { Campos } \\
\text { et al. } 2009 \\
{[23](N=70)}\end{array}$ & $\begin{array}{l}\text { Elkhoury } \\
\text { et al. } 2012 \\
{[24](N=855)}\end{array}$ & $\begin{array}{l}\text { Present study } \\
2012(N=251)\end{array}$ \\
\hline Fever & $72 / 82(87 \cdot 8)$ & 173/186 (93) & $23(100)$ & (81) & $(91 \cdot 6)$ & $233 / 246(95 \cdot 2)$ \\
\hline Dyspnoea & $54 / 82(65 \cdot 8)$ & $137 / 184(74 \cdot 5)$ & $23(100)$ & (34) & $(>80)$ & $175 / 243(72 \cdot 1)$ \\
\hline Cough & $67 / 81(82 \cdot 7)$ & $108 / 181(59 \cdot 7)$ & $17(74)$ & (44) & $(>70)$ & $149 / 244(61 \cdot 3)$ \\
\hline Acute respiratory failure & NI & $70 / 175(40)$ & NI & $(58 \cdot 8)$ & $(49 \cdot 1)$ & $107 / 245(43 \cdot 8)$ \\
\hline Myalgia & $66 / 81(81 \cdot 4)$ & $124 / 180(68 \cdot 8)$ & $18(78)$ & (18) & NI & $179 / 243(74 \cdot 1)$ \\
\hline Headache & $70 / 82(85 \cdot 3)$ & $143 / 180(79 \cdot 4)$ & $15(65)$ & (34) & $(>80)$ & $214 / 243(88 \cdot 3)$ \\
\hline Vomiting & $39 / 82(47 \cdot 5)$ & $107 / 177(60 \cdot 5)$ & $14(61)$ & (25) & $(>70)$ & $189 / 244(77 \cdot 0)$ \\
\hline Thoracic pain & 49/81 (60·4) & NI & $12(52)$ & NI & $(54 \cdot 7)$ & $131 / 243(53 \cdot 4)$ \\
\hline Abdominal pain & NI & NI & $11(48)$ & NI & $(54 \cdot 2)$ & $155 / 243(63 \cdot 6)$ \\
\hline Renal failure & NI & NI & $16(19)$ & NI & $(42 \cdot 5)$ & $38 / 241(33 \cdot 0)$ \\
\hline Petechiae and/or bleeding & NI & NI & $1(4)$ & (9) & $(18 \cdot 8)$ & $40 / 242(14 \cdot 5)$ \\
\hline Haematocrit $>50$ & $52 / 71(73 \cdot 2)$ & $83 / 146(44 \cdot 4)$ & $19(83)$ & (70) & $(57 \cdot 3)$ & $113 / 207(54 \cdot 7)$ \\
\hline Atypical lymphocytes & NI & $62 / 82(33 \cdot 2)$ & $9(39)$ & NI & $(23 \cdot 7)$ & $68 / 182(34 \cdot 7)$ \\
\hline Thrombocytopenia & 45/63 (71.4) & $96 / 135(51 \cdot 3)$ & $22(96)$ & (93) & $(78 \cdot 6)$ & $152 / 193(73 \cdot 0)$ \\
\hline Leukocytosis & $22 / 54(40 \cdot 7)$ & NI & $17 / 23(74)$ & (67) & $(50)$ & $83 / 179(45 \cdot 1)$ \\
\hline $\begin{array}{l}\text { Increase of BUN and } \\
\text { creatinine }\end{array}$ & $19 / 29(65 \cdot 5)$ & NI & $16(70)$ & $(42)^{*},(51) \dagger$ & $(42 \cdot 5) \dagger$ & $65 / 171(38 \cdot 0)$ \\
\hline Diffuse pulmonary infiltrate & $38 / 47(80 \cdot 8)$ & $105 / 133(56 \cdot 2)$ & $21 / 23(91 \cdot 2)$ & $12(41)$ & $(78 \cdot 9)$ & $121 / 192(62 \cdot 3)$ \\
\hline
\end{tabular}

HSS, Health Surveillance Secretariat; NI, not informed; BUN, blood urea nitrogen.

* Increase of urea.

$\dagger$ Increase of creatinine.

Table 4. Risk factors for death by hantavirus pulmonary syndrome according to final model in GLM, Santa Catarina, Brazil (1999-2011)

\begin{tabular}{lll}
\hline \hline Variable & OR $(95 \% \mathrm{CI})$ & $P$ value \\
\hline Mesoregion & & \\
Grande Florianópolis & Reference & Reference \\
North Santa Catarina & $2 \cdot 84(0 \cdot 68-12 \cdot 04)$ & $0 \cdot 149$ \\
Western Santa Catarina & $0 \cdot 89(0 \cdot 33-2 \cdot 54)$ & $0 \cdot 822$ \\
South Santa Catarina & $4 \cdot 53(0 \cdot 35-112 \cdot 43)$ & $0 \cdot 260$ \\
Vale do Itajai & $2 \cdot 88(0 \cdot 99-8 \cdot 81)$ & $0 \cdot 055$ \\
$\quad$ Mountain & $1 \cdot 51(0 \cdot 25-8 \cdot 27)$ & $0 \cdot 635$ \\
Increase of BUN and creatinine & $3 \cdot 26(1 \cdot 62-6 \cdot 7)^{*}$ & $0 \cdot 001$ \\
\hline \hline
\end{tabular}

OR, Odds ratio; CI, confidence interval; BUN, blood urea nitrogen.

* Significant by odds ratio.

(CBC) are commonly performed. In this scenario, HPS can resemble many other infectious diseases, especially dengue and leptospirosis, two of the most frequent endemic infectious diseases in Brazil. Such a misdiagnosis can lead to vigorous fluid administration, which may aggravate the respiratory failure associated with pulmonary inflammation in HPS. The frequency of mechanical ventilation, $41 \cdot 4 \%$, was similar to the $46.5 \%$ reported by a large study of 855 HPS patients in Brazil [24].

Although early healthcare management would be expected to be associated with a lower fatality rate, the highest fatality rate occurred in patients admitted to the hospital within the first 5 days of onset of symptoms, suggesting the occurrence of fulminant cases of 


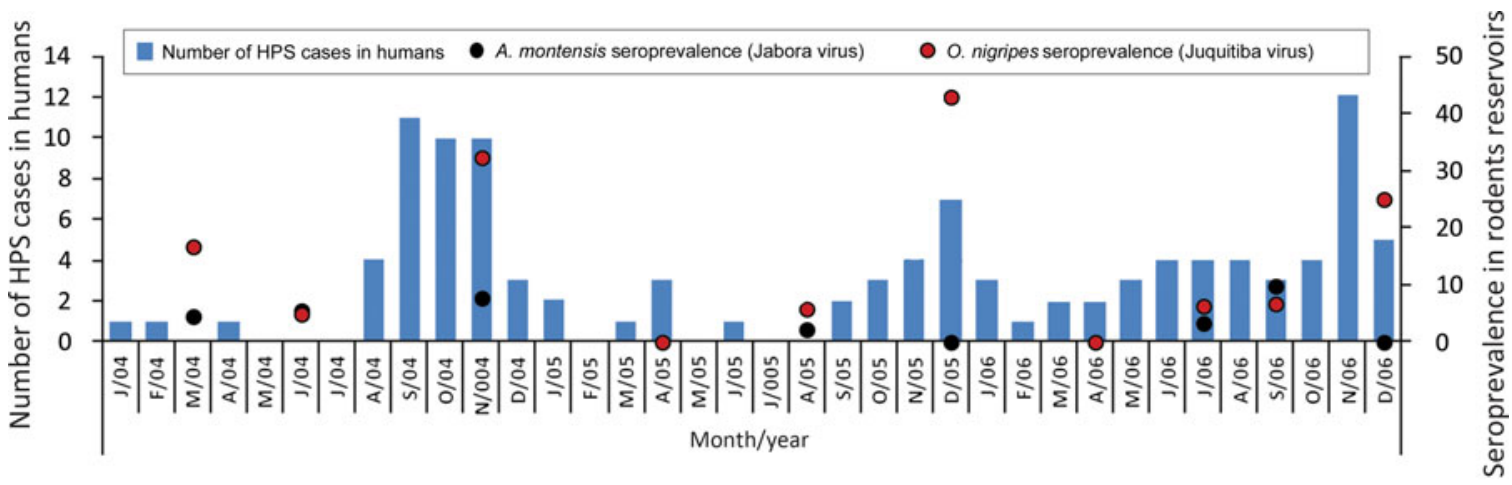

Fig. 4. Temporal correspondence of hantavirus pulmonary syndrome (HPS) cases and reservoir infection over a 3-year period. Blue bars, number of HPS cases in humans per month for the state of Santa Catarina (Brazil) from 2004 to 2006; black dots, observed hantavirus antibody prevalence in A. montensis (JABV host) by trapping session; red dots, observed hantavirus antibody prevalence in $O$. nigripes (JUQV host) by trapping session in Jaborá over the same period. Right scale, percentage of seropositive rodents in the trapped sample.

HPS. There was no difference in fatality between male and female patients, a finding that differs from that of a previous study [25]. HPS presents with a broad clinical spectrum, ranging from asymptomatic to oligosymptomatic, to fatal with fulminant pulmonary oedema. Host-related factors, the viral genotype and virus load might explain this wide variation [26-28]. Some hantaviruses are considered non-pathogenic to humans, although other factors that appear to contribute to the severity of the clinical characteristics can be related to the human host (histocompatibility complex) [29-31].

Although not confirmed by the OR analysis, the greater probability of the occurrence of death by HPS in $\mathrm{SC}$ was also associated with the locality; the highest fatality rate was observed in the northern SC and Vale do Itajaí regions. This result could be associated with the greater attention from health services in some regions, especially during the years with the largest number of cases. This could explain why although western SC has the highest number of cases it still shows the lowest fatality rate. Our result reinforces the need for adjusting surveillance tools and investigating other factors associated with this different fatality rate in SC.

In our series, the epidemiological results were consistent with the data reported in the literature [21-24]. Our results were consistent with the characterization of HPS as a disease of rural, predominantly male, agricultural workers in their productive years. The majority of cases occurring in residents of rural areas and agricultural and livestock (farming) activities are correlated with the risk of exposure to hantavirus in $60 \%$ of cases, characterizing HPS as a clearly work-related disease. Contact with rodents is extremely common in rural locations, and as expected, $64 \cdot 1 \%$ of the SC patients reported contact with rodents or rodent excreta.

Only seven $(2 \cdot 8 \%)$ cases occurred in children aged $<10$ years. Reports of HPS in individuals aged $<17$ years are uncommon. In the United States, $<1 \%$ of HPS cases were reported in individuals aged $<10$ years, and $<7 \%$ of HPS cases occurred in children aged $<17$ years [28, 32, 33]. In Argentina, 9.3\% of HPS cases were in children aged $<14$ years [25]. All of the clinical illnesses of the paediatric patients in these reports were similar to those observed in adult patients in these studies, as was the case in our study.

Unlike that observed in the country as a whole or in other regions, HPS has been reported to display a clear seasonal trend in the southern region of Brazil [4]. Similarly, in SC, the fact that the greatest number of cases was recorded between October and December suggests seasonality, probably related to the seasonal harvesting and storing of seeds (grains), especially corn. Thus far, the emergence of isolated cases or outbreaks of HPS in Brazil has been connected to particular situations or environmental risk factors, such as (1) an agricultural profile, as observed in most cases in SC, with the involvement of cornfields bordering forests; (2) an association with the construction of bunkers or other buildings that allow the entry of rodents and their consequent direct access to stored food or seeds; or (3) occupational exposures in which an employee might encounter a rodent or rodent droppings (e.g. corn bags) in cornfields or other crop seed fields. In general, the greatest risk of exposure to hantavirus is associated with entering closed buildings that are rodent-infested [21-24, 34]. Other factors, such as 
climate change, characteristics of the biotic environment (e.g. habitat quality and agricultural fields) and human activities and behaviour must be included as risk factors for sporadic outbreaks of hantavirus.

In SC, during the outbreak years of high incidence (2004 and 2006), HPS cases were detected mainly in municipalities where rodents outbreaks were reported after a widespread bamboo mast event. The 'taquaralixa' bamboo is endemic to the south Atlantic Forest, and had mast flowered in some areas of SC during 2004, 2005 and 2006. Known as ratada, the phenomenon of rodent outbreaks has been recorded in South America since the Spanish conquest, more specifically, in Brazil and Chile [35-37]. In 2006, 50\% of the HPS cases were reported in municipalities in which mast events occurred, as observed in the mesoregions of Vale do Itajai and Grande Florianópolis. This fact attracted the attention of the staff of the State Epidemiological Surveillance at the time (Epidemiologic Surveillance of Santa Catarina State, Report on Hantavirus cases 1999-2011, unpublished data). Thus, the information obtained in this historical series coupled with the occurrence of ratada reinforces a possible direct association between bamboo mast events, rodent population outbreaks and HPS cases.

In a previous longitudinal study of hantavirus infection in rodents in Jaborá, located in the midwestern region of the state, the co-circulation of two different genotypes in three different rodent species was reported: JABV in Akodon paranaensis and A. montensis and $\mathrm{JUQV}$ in $O$. nigripes $[14,38]$. JABV in $A$. montensis and JUQV in $O$. nigripes were also observed by Chu et al. in Paraguay [39]. Our previous study described the genetic analysis performed on samples from rodents captured at the presumed site of infection of one human patient (case 4, Supplementary Table S1) during the mast seeding events in Jaborá [14]. Furthermore, we found that highest number of infected animals with JUQV was found in November and December, months with a high incidence of human HPS cases in SC.

Greater awareness of the fact that HPS can occur simultaneously with dengue or leptospirosis is needed, especially in critically ill patients, in whom the diagnosis can easily be missed if not suspected, and vigorous fluid administration may aggravate the respiratory failure associated with pulmonary inflammation. Emergency physicians should be aware of rodent outbreaks and be vigilant for hantavirus exposures, including ecotourism activities, especially during the summer and early autumn. The observation that ratadas occurred during the years with a high incidence of
HPS cases in SC underscores the importance of analysing the association of HPS with bamboo mast events and rodent population outbreaks, especially in southern Brazil. Moreover, the possible existence of another hantavirus genotype associated with asymptomatic infection or mild disease could explain the lower case-fatality rate in this area of Brazil and should be continuously investigated.

\section{SUPPLEMENTARY MATERIAL}

For supplementary material accompanying this paper visit http://dx.doi.org/10.1017/S0950268815002460.

\section{ACKNOWLEDGEMENTS}

We thank Luciana Helena Bassan and Endiá Almeida for technical support (IOC/FIOCRUZ). We also thank Maria Angélica Mares-Guia, Mônica de Avelar Figueiredo Mafra Magalhães e Renata de Saldanha da Gama Gracie Carrijo (Sector for geoprocessing/ICICT) for image production and treatment assistance, FIOCRUZ. We are also grateful to Bernardo Rodrigues Teixeira for assistance in the revision and final analysis.

\section{DECLARATION OF INTEREST}

None.

\section{REFERENCES}

1. Iversson LB, et al. Human infection by hantavirus in southern and southeastern Brazil. Revista da Associação Médica Brasileira 1994; 40: 85-92.

2. Silva MV, et al. Hantavirus pulmonary syndrome. Report of the first three cases in São Paulo, Brazil. Revista do Instituto de Medicina Tropical de São Paulo 1997; 39: 231-234.

3. Brazilian Ministry of Health. Confirmed cases of hantavirus diseases. Brazil, major regions and federative units, 1993 to 2014 (http://portalsaude.saude.gov.br/ index.php/o-ministerio/principal/secretarias/svs/hantavirose). Accessed 10 March 2015.

4. Pinto Junior VL, et al. Twenty years of hantavirus pulmonary syndrome in Brazil: a review of epidemiological and clinical aspects. Journal of Infection in Developing Countries 2014; 8: 137-142.

5. Willemann MC, Oliveira SV. Risk factors associated with hantavirus fatality: a regional analysis from a case-control study in Brazil. Revista da Sociedade Brasileira de Medicina Tropical 2014; 47: 47-51.

6. Johnson AM, et al. Genetic investigation of novel hantaviruses causing fatal HPS in Brazil. Journal of Medical Virology 1999; 59: 527-535. 
7. Suzuki A, et al. Identifying rodent hantavirus reservoirs, Brazil. Emerging Infectious Diseases 2004; 10: 2127-2134.

8. Rosa ES, et al. Newly recognized hantaviruses associated with hantavirus pulmonary syndrome in Northern Brazil: partial genetic characterization of viruses and serologic implication of likely reservoirs. Vector Borne and Zoonotic Diseases 2005; 5: 11-19.

9. Travassos da Rosa ES, et al. Pygmy rice rat as potential host of Castelo dos Sonhos hantavirus. Emerging Infectious Diseases 2011; 17: 1527-1530.

10. Travassos da Rosa ES, et al. Molecular epidemiology of Laguna Negra virus, Mato Grosso State, Brazil. Emerging Infectious Diseases 2012; 18: 982-985.

11. Firth C, et al. Diversity and distribution of hantaviruses in South America. Journal of Virology 2012; 86: 13756-13766.

12. Oliveira RC, et al. Hantavirus reservoirs: current status with an emphasis on data from Brazil. Viruses 2014; 6: 1929-1973.

13. Weksler M, Bonvicino CR. Genus Oligoryzomys Bangs, 1900. In: Patton JL, Pardiñas UFJ, D'Elía G, eds. Mammals of South America. Chicago: The University of Chicago Press, 2015, pp. 1305-1375.

14. Oliveira RC, et al. Genetic characterization of hantaviruses associated with sigmodontine rodents in an endemic area for hantavirus pulmonary syndrome in southern Brazil. Vector Borne and Zoonotic Diseases 2011; 11: 301-314.

15. Health Surveillance Guide. Brazilian Ministry of Health. Health Surveillance Secretariat. Hantavirus Diseases. Brasília, DF, Brazil: Ministry of Health, 2014, pp. 637-650.

16. Oliveira RC, et al. Ecological study of hantavirus infection in wild rodents in an endemic area in Brazil. Acta Tropica 2014; 131: 1-10.

17. Oliveira RC, et al. Genetic characterization of a Juquitiba-like viral lineage in Oligoryzomys nigripes in Rio de Janeiro, Brazil. Acta Tropica 2009; 112: 212-218.

18. Guterres A, et al. Phylogenetic analysis of the $\mathrm{S}$ segment from Juquitiba hantavirus: identification of two distinct lineages in Oligoryzomys nigripes. Infection, Genetics and Evolution 2013; 18: 262-268.

19. Gouy M, Guindon S, Gascuel O. SeaView version 4: a multiplatform graphical user interface for sequence alignment and phylogenetic tree building. Molecular Biology and Evolution 2010; 27 :221-224.

20. Ronquist F, Huelsenbeck JP. MrBayes 3: Bayesian phylogenetic inference under mixed models. Bioinformatics 2003; 19: 1572-1574.

21. Raboni SM, et al. Hantaviruses in Central South America: phylogenetic analysis of the $\mathrm{S}$ segment from HPS cases in Paraná, Brazil. Journal of Medical Virology 2005; 76: 553-562.

22. Limongi JE, et al. Hantavirus cardiopulmonary syndrome in the Triângulo Mineiro and Alto Paranaíba regions, State of Minas Gerais, 1998-2005: Clinical-epidemiological aspects of 23 cases. Journal of the Brazilian Society of Tropical Medicine 2007; 40: 295-299.

23. Campos GM, et al. Pulmonary and cardiovascular syndrome due to hantavirus: clinical aspects of an emerging disease in southeastern Brazil. Revista da Sociedade Brasileira de Medicina Tropical 2009; 42: 282-289.
24. Elkhoury MR, et al. Hantavirus pulmonary syndrome: prognostic factors for death in reported cases in Brazil. Transactions of the Royal Society of Tropical Medicine and Hygiene 2012; 106: 298-302.

25. Martinez VP, et al. Hantavirus pulmonary syndrome in Argentina, 1995-2008. Emerging Infectious Diseases 2010; 16: 1853-1860.

26. Khan AS, et al. Hantavirus pulmonary syndrome: the first 100 US cases. Journal of Infectious Diseases 1996; 173:1297-1303.

27. Hjelle B, Torres-Pérez F. Hantaviruses in the Americas and their role as emerging pathogens review. Viruses 2010; 2: 2559-2586.

28. MacNeil A, Ksiazek TG, Rollin PE. Hantavirus pulmonary syndrome, United States, 1993-2009. Emerging Infectious Diseases 2011; 17: 1195-1201.

29. Plyusnin A, et al. Dobrava hantavirus in Estonia: does the virus exist throughout Europe? Lancet 1997; 349: $1369-1370$.

30. Mustonen J, et al. Epidemiology of hantavirus infections in Europe. Nephrology Dialysis Transplantation 1998; 13: 2729-2731.

31. Kilpatrick ED, et al. Role of specific CD8+ T cells in the severity of a fulminant zoonotic viral hemorrhagic fever, Hantavirus Pulmonary Syndrome. Journal of Immunology 2004; 172: 3297-3304.

32. Ramos MM, et al. Infection with Sin Nombre hantavirus: clinical presentation and outcome in children and adolescents. Pediatrics 2001; 108: eE27.

33. Centers for Disease Control and Prevention. Hantavirus pulmonary syndrome in five pediatric patients - four states, 2009. Morbidity and Mortality Weekly Report 2009; 58: 1409-1412.

34. Pinto Jr. VL, de Sousa AI, de Lemos ER. Regional variations and time trends of hantavirus pulmonary syndrome in Brazil. Epidemiology and Infection 2014; 142: 2166-71.

35. Pereira C. Rodent outbreak in southern Brazil and the growth cycle of bamboo. Archive of Biological Institute of São Paulo 1941; 12: 175-195.

36. Jaksic FM, Lima M. Myths and facts on 'ratadas': bamboo blooms, rainfall peaks and mouse outbreaks. Austral Ecology 2003; 28: 237-251.

37. de Oliveira, SV et al. Research on rodent outbreak associated with flowering and fruiting of bamboos in São Francisco do Sul, Santa Catarina, Brazil, 2012. Bahia Journal of Public Health 2013; 37: 1071-1079.

38. Oliveira RC, et al. Detection of the first incidence of Akodon paranaensis naturally infected with the Jabora virus strain (Hantavirus) in Brazil. Memórias do Instituto Oswaldo Cruz 2012; 107: 424-428.

39. Chu YK, et al. Sympatry of 2 hantavirus strains, Paraguay, 2003-2007. Emerging Infectious Diseases 2009; 15: 1977-1980.

40. Health Surveillance Secretariat. Cardiopulmonary syndrome hantavirus in Brazil in 2006: clinical and epidemiological characteristics. Epidemiological Electronic Newsletter, 2007 (http://portalsaude.saude.gov.br/index. php/o-ministerio/principal/leia-mais-o-ministerio/197secretaria-svs/11955-boletins-epidemiologicos-arquivos). Accessed 20 October 2013. 